\title{
Estimation of the risk of death during the first year after acute myocardial infarction from systolic time intervals during the first week
}

\author{
B J NORTHOVER \\ From the Leicester Royal Infirmary, Leicester
}

SUMMARY Patients who survived for the first seven days after acute myocardial infarction were followed up for a further 51 weeks. During these 51 weeks there were 123 deaths and 477 eventual survivors. Approximately half of the deaths occurred during the first 3 weeks of follow up. The deaths were predicted with $75 \%$ sensitivity and $73 \%$ specificity by a discriminant analysis based upon six variables seen during the first 7 days; predictions of death and survival were $55 \%$ and $92 \%$ accurate respectively. These six variables were, in ascending order of prognostic importance, the occurrence of bundle branch blocks, the administration of a diuretic, the age of the patient, the presence of diabetes mellitus, a previous myocardial infarction, and the ratio of the measured left ventricular pre-ejection and ejection periods. Many other monitored variables, although univariately associated with death, contributed nothing further to the multivariate assessment of mortality risk.

Most deaths from myocardial infarction occur within the first few days. Nevertheless, patients who survive for a week in hospital remain at increased risk of death, albeit diminishing risk, for several months thereafter. ${ }^{12}$ Many such delayed deaths, although not all, occur suddenly and outside hospital. Most are considered to be caused by cardiac arrhythmias. ${ }^{34}$ Approximately $16 \%$ of patients who currently leave hospital alive after acute myocardial infarction die during the remainder of the first year. ${ }^{5}$ Prophylactic agents intended to reduce this delayed mortality are available. ${ }^{6}$ Such agents would best be confined, however, to the subgroup of individuals at greatest risk of death during the first few months after infarction. But can the high risk subgroup of patients be identified while still in hospital?

Numerous features have been shown to be statistically associated with subsequent death, ${ }^{7}$ but to varying degrees in different reported series. This is particularly true of cardiac rhythm disturbances that occur while patients are in hospital. ${ }^{89}$ Disagreement continues about whether arrhythmias constitute

Requests for reprints to Dr B J Northover, Coronary Care Unit, Leicester Royal Infirmary, Leicester LE1 5WW.

Accepted for publication 10 August 1989 prognostically adverse features operating independently of those other adverse features that often coexist. ${ }^{10-12}$ Left ventricular failure, on the other hand, has been shown consistently to be independently associated with death. ${ }^{13-15}$ Nevertheless, little information is available on which haemodynamic feature of cardiac failure, which test for its presence, and which measure of its severity are prognostically most reliable. Moreover, the time after infarction at which collection of this information is most meaningful is presently unknown. These matters were investigated in the present study, with an emphasis upon observations and tests that are sufficiently safe and easy to use for them to be available in even a non-specialist general hospital, and which were applicable within the first week to all patients, irrespective of age, severity of infarction, or the presence of concomitant disease. Early assessment is essential because many patients die within a few weeks of discharge. ${ }^{1}$ Furthermore, the procedures used must be applicable to even the oldest and frailest patients because they are the most likely to die. ${ }^{5}$

\section{Patients and methods}

Patients admitted to the Leicester Royal Infirmary who fulfilled the World Health Organisation's 
criteria for a "definite acute myocardial infarction"16 and who survived for the first 7 days were studied prospectively for the remainder of the first year. A total of 600 consecutive episodes of infarction, all managed by the same consultant, form the basis of this report. No eligible patient was excluded during the study period. The policies and techniques used for monitoring and managing such patients in this hospital, both in the coronary care unit and after transfer to general medical wards, have been described previously. ${ }^{17} 18$ No patient received thrombolytic treatment. On each of the first 2 or 3 days in hospital the following routine tests and investigations were performed on all patients: $(a)$ a chest radiograph was obtained with a mobile $x$ ray source; $(b)$ a standard 12 lead electrocardiogram was recorded; $(c)$ venous blood serum was analysed for creatine kinase, hydroxybutyrate dehydrogenase, alkaline phosphatase, glutamyl transferase, bilirubin, urea, creatinine, urate, sodium, potassium, bicarbonate, calcium, and phosphate; and $(d)$ left ventricular systolic time intervals were measured on a simultaneously recorded electrocardiogram, phonocardiogram, and externally registered carotid artery pulse, as described in detail elsewhere. ${ }^{1718}$ The ratio of left ventricular pre-ejection and ejection periods (PEP/ EP) is known to have the greatest prognostic value. ${ }^{17} 18$ This ratio also has the convenience of being largely independent of heart rate. The PEP/EP ratios were already known to divide patients at the time of admission to this hospital into five prognostic strata with mortalities ranging from $4 \%$ to $62 \%$ during the first 7 days. ${ }^{17} 18$ These same strata were used in the present study. Anatomical site of infarction was classified electrocardiographically by familiar but arbitrary criteria. ${ }^{1920}$

Patients were routinely examined every day by me while they were in hospital, and I paid particular attention to features of cardiac failure (table 1). On day $5 \mathrm{PEP} / \mathrm{EP}$ ratios were remeasured in all patients and an electrocardiogram was tape recorded for 24 hours on all patients. I analysed tape recordings by procedures that have been described and validated previously. ${ }^{21}$ Most disturbances of rhythm were classified according to the criteria of Schamroth ${ }^{22}$ (table 2). Intraventricular conduction defects, however, were classified according to the World Health Organisation's criteria, ${ }^{23}$ except that fascicular blocks were ignored. Tape recorded ventricular extrasystoles and paroxysms of ventricular tachycardia were graded in various ways (table 2), including that proposed by Lown and Wolf. ${ }^{24}$

A signal averaged electrocardiogram was obtained from 506 patients during the fifth day in hospital. Frank orthogonal bipolar leads $\mathrm{X}, \mathrm{Y}$, and $\mathrm{Z}$ were recorded simultaneously for $10 \mathrm{~min}$ with the patient at rest. Averaging was performed by the methods of Simson $^{25}$ with a commercially available system $\stackrel{.}{\Rightarrow}$ (model 101, made by Arrhythmia Research Technology of Oklahoma). Averaging was not attemptedo in the remaining 94 patients who had atrial fibrilla- $-\underline{\underline{F}}$ tion, atrial flutter, bundle branch blocks, ${ }^{26}$ or $\frac{\overline{\bar{c}}}{\overline{0}}$ extrasystoles occurring at a frequency of $>10 / \mathrm{min} . \stackrel{\varnothing}{\Omega}$ Less frequent extrasystoles were automatically@ deleted by a template algorithm within the computer $\vec{A}$ program. At least 200 sinus beats were bidirection- ally bandpass-filtered between 25 and $250 \mathrm{~Hz}$. This $\vec{\omega}$ provided a noise level of $\langle 1 \mu \mathrm{V}$ in all cases. A root $\stackrel{\circ}{\circ}$ mean square voltage in the final $40 \mathrm{~ms}$ of the averaged QRS complex of $\leqslant 25 \mu \mathrm{V}$ or an averaged QRS duration of $\geqslant 120 \mathrm{~ms}$ was taken to be a significant lateos potential. ${ }^{25}$

No patient was lost to follow up, which was from 6 the beginning of day 8 to the end of day 365 . Surviving patients were seen in outpatient clinics for

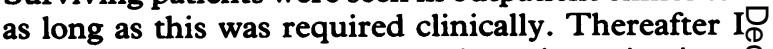
contacted patients. All medications, investigations, and operations were documented during follow up,, 3 as were further myocardial infarctions, diagnosedథ according to the same criteria used for the index $\vec{c}$ infarction. Exercise electrocardiography was under-o taken by 113 patients, predominantly younger men, a median of 22 weeks after infarction. The results ofo this test were not used in the statistical analysis of this 5 study because no patient who died had taken the test a pattern noted previously by others. ${ }^{79}$ Coronaryo angiography was performed on 29 patients after? infarction (median 37 weeks), although only six $\overrightarrow{\overrightarrow{0}}$ patients had coronary angioplasty or aorto-coronary bypass surgery during follow up.

Death was the primary patient end point that studied. All hospital records relating to the period of follow up were scrutinised, but many of the deaths occurred outside hospital, usually at home. In sucho cases the person who witnessed the event was contac 3 . ted, or failing that the person who discovered or certified death. Information was routinely collected on the date and time of death, the patient's activitieso before death, and the time that elapsed between anys premonitory events and death.

All the routinely monitored variables, as defined in tables $1-3$, from all 600 patients in the study were categorised for statistical analysis into two or more bands-most often simply presence or absence ${ }_{\omega}^{N}$ More complex categories are defined in the text and tables. Statistical associations between all possibles pairs of routinely monitored variables and betweer each monitored variable and patient end point werêt then assessed by $\chi^{2}$ tests plus a stepwise linearo discriminant analysis contained in the Statistica $\bar{Q}$ Package for the Social Sciences. ${ }^{27}$ This permitted both univariate and multivariate associations to 
Table 1 Routinely monitored variables that may be related to the effectiveness of cardiac pumping

\begin{tabular}{|c|c|c|}
\hline & \multicolumn{2}{|c|}{ Numbers of patients } \\
\hline & $\begin{array}{l}\text { With } \\
\text { feature }\end{array}$ & $\begin{array}{l}\text { With feature } \\
\text { who died }\end{array}$ \\
\hline \multicolumn{3}{|l|}{ Lung crepitation: } \\
\hline Day of admission & - & - \\
\hline Day of discharge* & 32 & 13 \\
\hline Any day* & 293 & 75 \\
\hline Above lower scapular margin on any day & 74 & 23 \\
\hline \multicolumn{3}{|l|}{ Gallop rhythm (i) third, (ii) fourth, (iii) summation: } \\
\hline Day of admission ( $\star_{\text {for }} \mathrm{i}$ and $\mathrm{iii}$ ) & 58 (i or iii) & 19 \\
\hline Day of discharge ( ${ }^{\star}$ for $\mathrm{i}$ and $\left.\mathrm{iii}\right)$ & 66 (i or iii) & 25 \\
\hline Any day ( ${ }^{\star}$ for $\mathrm{i}$ and $\left.\mathrm{iii}\right)$ & 81 (i or $\mathrm{iii})$ & 28 \\
\hline \multicolumn{3}{|l|}{ Cardiac apical impulse on day 5 : } \\
\hline Palpability & - & - \\
\hline To left of mid-clavicular line $(\mathrm{cm})$ & - & - \\
\hline Dyskinetic & - & - \\
\hline Diameter $>4 \mathrm{~cm}^{\star}$ & 110 & 35 \\
\hline Jugular pulsations $>3 \mathrm{~cm}$ above sternal notch ${ }^{\star}$ & 115 & 40 \\
\hline \multicolumn{3}{|l|}{ Oedema on any day: } \\
\hline Feet or ankles $\star$ & 67 & 24 \\
\hline $\begin{array}{l}\text { Above mid-calf* } \\
\text { Sacral }\end{array}$ & 26 & 11 \\
\hline \multicolumn{3}{|l|}{$\begin{array}{l}\text { Sacral } \\
\text { Blood urea > upper limit of normal range: }\end{array}$} \\
\hline Day of admission * & 162 & 53 \\
\hline Maximum in hospital* & 280 & 75 \\
\hline \multicolumn{3}{|l|}{ Anterior-posterior radiograph at admission: } \\
\hline Pulmonary venous imbalance ${ }^{\star}$ & 204 & 59 \\
\hline Pulmonary oedema ${ }^{\star}$ & 59 & 20 \\
\hline Pleural effusion* ${ }^{\star}$ & 22 & 13 \\
\hline \multicolumn{3}{|l|}{ Radiographic evidence on any day: } \\
\hline Pulmonary venous imbalance ${ }^{\star}$ & 213 & 61 \\
\hline Pulmonary oedema ${ }^{\star}$ & 71 & 35 \\
\hline Pleural effusion $\star$ & 70 & 40 \\
\hline Maximum cardiothoracic ratio $>0.5$ on any day ${ }^{\star}$ & 220 & 68 \\
\hline \multicolumn{3}{|l|}{ 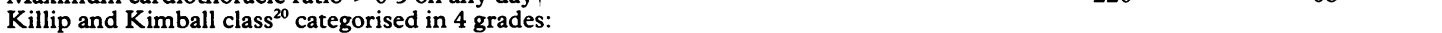 } \\
\hline Day of admission ${ }^{\star}$ & $273(\geqslant 2)$ & 77 \\
\hline Worst score in hospital ${ }^{\star}$ & $296(\geqslant 2)$ & 78 \\
\hline \multicolumn{3}{|c|}{ Prognostic index of Norris and co-workers, ${ }^{5}$ categorised as $<3,3-5,6-8,9-11$, or $>11$ : } \\
\hline Day of admission ${ }^{\star}$ & $265(\geqslant 3)$ & 75 \\
\hline Worst score in hospital ${ }^{\star}$ & $304(\geqslant 3)$ & 82 \\
\hline
\end{tabular}

$\star$ Indicates a significant univariate association with non-survival. All features were categorised as present or absent unless specified otherwise. †Indicates radiographic information derived from an erect posterior-anterior film with the $x$ ray source 6 feet from the chest.

be assessed, with $\mathrm{p}<0.05$ being regarded as significant. This method for predicting outcome after myocardial infarction is well established. . $^{2-30}$

As progressively more patients completed their year of follow up it became possible by means of discriminant analyses to calculate on day 7 the probability that each subsequently enrolled patient would survive for a year, based upon multivariate comparison of the patient's own characteristics with those of all preceding patients in the study. At the end of the year of follow up the actual and predicted outcomes were compared. Predictions only became maximally successful, however, after the first 190 patients had completed their follow up.

\section{Results}

A total of 123 patients died during follow up $(20 \%$ of the study population); 61 of the deaths occurred within the first month. Time of death was known to the nearest hour in 95 patients. Of the accurately timed deaths, 39 occurred between $05.00 \mathrm{~h}$ and $11.00 \mathrm{~h}$, which is significantly more than occurred during any other consecutive $6 \mathrm{~h}$ period, confirming previous findings. ${ }^{31}$ No consistent pattern of antecedent activities or premonitory events was discovered. Death seemed to be unexpected in $57 \%$ whose death was witnessed.

Many of the routinely monitored variables in the present study, as defined in tables 1-3, were univariately associated with death. This was expected because the variables had been chosen because an association with death was envisaged. Discriminant analysis was performed to identify which routinely monitored variables were multivariately predictive of death. When all routinely monitored variables were included predictions were $75 \%$ sensitive and $73 \%$ specific, with the predictive accuracy of death and survival being $55 \%$ and $92 \%$ respectively. Each monitored variable was then omitted in turn in 
Table 2 Disturbances of ventricular rhythm routinely tape recorded on day 5

\begin{tabular}{|c|c|c|}
\hline \multirow[b]{2}{*}{ Feature } & \multicolumn{2}{|c|}{ Numbers of patients } \\
\hline & $\begin{array}{l}\text { With } \\
\text { feature }\end{array}$ & $\begin{array}{l}\text { With feature } \\
\text { who died }\end{array}$ \\
\hline $\begin{array}{l}\text { VEs } \geqslant 1 / \text { hour } \\
\text { Multifocal VEs } \\
\text { Paired VEs } \\
\text { VEs in bigeminy } \\
\text { Early VEs }\left(R^{\prime} / Q T<1\right) \\
\text { AIVR } \\
\text { VT } \\
\text { Highest VT rate }(100-200 / \mathrm{min} \text { or }>200 / \mathrm{min}) \\
\text { Number of paroxysms of VT } \\
\text { Longest paroxysm of VT (beats and seconds) }\end{array}$ & $\begin{array}{r}117 \\
85 \\
64 \\
79 \\
\frac{28}{57} \\
- \\
-\end{array}$ & $\begin{array}{l}36 \\
25 \\
21 \\
28 \\
11 \\
19 \\
- \\
-\end{array}$ \\
\hline
\end{tabular}

Arrhythmias were classified as present or absent unless specified above. With the exception of early VEs, all other listed features were univariately significantly associated with PEP/EP ratios on day 5 and with death.

$\star$ VEs, ventricular extrasystoles. Values of 1-10 VEs/hour and >10 VEs/hour were also univariately associated with death.

AIVR, accelerated idioventricular rhythm ( $\geqslant 3$ consecutive $Q R S$ complexes at $<100 / \mathrm{min}$ ).

VT, ventricular tachycardia ( $\geqslant 3$ consecutive $Q R S$ complexes at $\geqslant 100 / \mathrm{min}$ ).

reverse order of closeness of univariate association with death. Most single variables could be omitted without reducing the predictive sensitivity, specificity, or accuracy. One by one such variables were eliminated until only six remained. These six variables were, in diminishing order of their respective standardised canonical discriminant function coefficients $^{30}$ (used here as a convenient measure of prognostic impact): (a) the PEP/EP ratio on day 5 categorised as $<0.30=1,0.30-0.33=2,0.34$ $0.37=3, \quad 0.38-0.41=4,>0.41=5 ; \quad(b)$ the number of previous myocardial infarctions (MI) the patient was known to have sustained, diagnosed by the same criteria that were used for the index infarction; (c) whether the patient had diabetes mellitus (DM) categorised as present $=1$, absent $=0 ;(d)$ the age group in years of the patient, categorised as $<40=3 ; 40-50=4,51-60=5$, $61-70=6,71-80=7$, and $>80=8$; $(e)$ whether a diuretic drug with a direct renal action was administered at any stage in hospital, categorised as used $=1$, not used $=0$; and $(f)$ whether right or left bundle branch block (BBB) was shown while in hospital, categorised as shown $=1$, not shown $=0$. In com- bination these six variables were as successful as the combination of all the routinely monitored variables. These six variables could be combined in the follow- $-\Phi$ ing equation: Risk $=0.61(\mathrm{PEP} / \mathrm{EP})+0.92(\mathrm{MI})+\frac{3}{0}$ $0.93(\mathrm{DM})+0.28$ (age group) +0.53 (diuretic) $+\stackrel{\mathbb{Q}}{-}$ $0 \cdot 28$ (BBB). Each term in this equation is the product $\overrightarrow{0}$ of the non-standardised canonical discriminant func- 0 tion coefficient for that variable and the patient's own. value for the variable. Where the risk was $>2.73$ theo patient had $>50 \%$ chance of death during follow up and was classed as a predicted non-survivor. Patientso with a $<30 \%$ chance of death during follow up had $\mathrm{a}$ calculated risk of $<2.31$, and those with a $<10 \%$ chance of death had a calculated risk of $<2.04$.

Discriminant analysis with uncategorised values for age and the PEP/EP ratio gave essentially the same mortality predictions as those using the categories defined above. Categorised data, however, simplified the calculation of risk, even to the point of making it possible by mental arithmetic.

Any multivariate analytical technique makes certain assumptions about the numerical distribution of the data it is called upon to handle. If the assumptions are not fulfilled the predictive effective-o

Table 3 Probabilities that the univariate associations between the monitored variables and outcomes were due to chance

\begin{tabular}{|c|c|c|c|c|c|c|c|}
\hline & $P E P / E P$ & $M I$ & $D M$ & Age group & Diuretic & $B B B$ & $\tilde{c}$ \\
\hline $\begin{array}{l}\text { Non-survival } \\
\text { PEP/EP } \\
\text { MI } \\
\text { DM } \\
\text { Age group } \\
\text { Diuretic }\end{array}$ & $<0.001^{\star}$ & $\begin{array}{l}<0.001^{\star} \\
<0.001\end{array}$ & $\begin{array}{l}0.001^{\star} \\
0.047^{\star} \\
0.230\end{array}$ & $\begin{array}{c}0.001^{\star} \\
<0.001^{\star} \\
0.990 \\
0.185\end{array}$ & $\begin{array}{r}<0.001^{\star} \\
<0.001^{\star} \\
0.003^{\star} \\
<0.001^{\star} \\
0.002^{\star}\end{array}$ & $\begin{array}{c}<0.001^{\star} \\
<0.010^{\star} \\
0.297 \\
0.149 \\
0.059 \\
0.005^{\star}\end{array}$ & 告 \\
\hline
\end{tabular}

PEP/EP, ratio of pre-ejection and ejection periods on day 5 ( $\geqslant 0.30$ in 257, of whom 96 died); MI, number of previous myocardialn infarctions ( $\geqslant 1$ in 117, of whom 48 died); DM, diabetic status (121 diabetic patients, of whom 39 died); Age group, age in years, by decade (159 patients > 70 years, of whom 50 died); Diuretic, treatment with a diuretic drug while in hospital ( 317 treated patients, of whom 92 died); BBB, right and left bundle branch blocks while in hospital (present in 92, of whom 35 died). ${ }^{\star}$ Univariate association between the indicated variables was significant. 
ness may be reduced. The data derived from the present study were re-examined, therefore, by two additional techniques, namely logistic regression and the Cox model. The same six routinely monitored variables (table 3 ) were most predictive of mortality in all three methods of analysis. The Cox model, however, identified third degree atrioventricular block as a seventh independent contributor, but this was of marginal significance. Logistic regression was slightly less sensitive $(73 \%)$ than discriminant analysis and the Cox model was slightly less specific $(70 \%)$ than either discriminant analysis or logistic regression. Because of the slight predictive superiority of discriminant analysis $I$ have used this for the remainder of this report.

Despite statistical independence for predictive purposes, each of the six variables listed in table 3 was also highly associated univariately with at least one of the other five. Patients who died without any warning were very similar in terms of these six variables to patients whose death came more gradually or after particular patterns of premonitory events. Only two patients died from apparently non-cardiac causes; one had a cerebrovascular accident and the other died of carcinomatosis.

Most of the routinely monitored variables in the present study owed whatever univariate association with death that they had (tables 1 and 2) to being associated with one or more of the six primary variables listed in table 3 . For example, many of the monitored variables reflecting reduced pumping effectiveness of the left ventricle (table 1) were closely associated univariately with death but contributed nothing additional to PEP/EP ratios on day 5 in the multivariate assessment of risk. This was also true of PEP/EP values measured on days other than day 5 . There was a univariate association between death and infarction of the anterior wall, compared with other sites, but this feature also failed to contribute multivariately to mortality risk.

Only one routinely monitored variable reflecting ventricular pumping effectiveness was found to be predictive of death independently of PEP/EP values on day 5, and that was diuretic use (table 3 ). This remained true irrespective of whether diuretic use was defined in terms of day of admission only, the last day in hospital, or indeed any day or combination of days in hospital. It was also independent of the type of diuretic used, the dose used, or the route by which it was administered. The highest standardised canonical discriminant function coefficient was obtained when this variable was defined in terms of "at any time in hospital", and it is in this sense that the variable is used in the remainder of this report. Diuretic usage was only marginally less predictive of death, however, when use on only the first day in hospital was considered.
Several disturbances of cardiac rhythm recorded on the routine daily 12 lead electrocardiograms, plus those on the routinely tape recorded electrocardiogram on day 5 , were univariately associated with death. This was true of episodes of second and third degree atrioventricular block, of atrial fibrillation, of atrial flutter, and of all forms of supraventricular tachycardia combined. Ventricular extrasystoles on the tape recorded electrocardiogram were univariately associated with death, and the association was closest when the frequency of these beats was categorised as $<1,1-10$, or $>10$ per hour (table 2 ). Table 2 shows several other features of the ventricular extrasystoles, such as grading according to the scheme of Lown and Wolf ${ }^{24}$ or occurrence in bigeminy or pairs, which although still significantly associated univariately with death, were less closely associated with this outcome than when the frequency of ventricular extrasystoles was defined as in table 2. Paroxysms of ventricular tachycardia on the tape recorded electrocardiogram had a similar prognostic significance to that of the frequency of ventricular extrasystoles. This was true irrespective of whether this arrhythmia was defined independently of the ventricular rate, or was categorised in three bands with average rates of $<100,100-200$, and $>200$ per min. Severity attribution was to the band representing the paroxysm with the highest rate. The prognostic significance of ventricular tachycardia was independent of the length of the longest paroxysm, the average length of the recorded paroxysms, or the total number of paroxysms during the 24 hour recording (table 2). None of the forgoing arrhythmias, however, made an independent contribution to mortality risk after allowance for the six variables shown in table 3 , and was seemingly independent of whether a patient was receiving antiarrhythmic drugs on day 5 , or had done so earlier while in hospital.

The occurrence of supraventricular extrasystoles on the electrocardiogram tape recorded on day 5 , or the occurrence of ventricular fibrillation while in hospital were not associated univariately with death during follow up. ${ }^{32-34}$

Late potentials were found in 168 of the 506 signalaveraged electrocardiograms and were significantly associated univariately with death. They made no independent contribution to mortality risk, however, in these 506 patients after allowance for the six variables listed in table 3 . Late potentials and tape recorded paroxysms of ventricular tachycardia showed a univariate association, and both were associated univariately with frequent ventricular extrasystoles on the tape recorded electrocardiogram.

To determine whether the prognostic significance of each of the routinely monitored variables changed 
significantly during the study period a discriminant analysis was performed on just the first 200 patients. This predicted the first year outcomes with $74 \%$ sensitivity, $74 \%$ specificity, and $56 \%$ accuracy for death. Unstandardised canonical discriminant function coefficients were calculated for each of the monitored variables in these first 200 patients. The coefficients were then used, without modification, to predict outcome in the remaining 400 patients. Predictions made in this way were $74 \%$ sensitive, $73 \%$ specific, and $55 \%$ accurate for death.

All survival predictions presented so far in this report relate to a 51 week period of follow up. Discriminant analyses were also undertaken to examine the predictability of survival for shorter periods. The 3 month predictions were $76 \%$ sensitive, $75 \%$ specific, and $55 \%$ accurate for death, values not significantly different from the one year predictions, and with the same six variables (table 3 ) contributing. This was not very surprising because a substantial majority of the deaths occurred within the first 3 months.

\section{Discussion}

As in several previous reports, ${ }^{13-15}$ patients in the present study with evidence of cardiac failure while in hospital had a high one year mortality. The most useful measure of cardiac pumping effectiveness from the list of routinely monitored variables was the ratio of the measured left ventricular pre-ejection and ejection periods on day 5 . Previous workers also have reported a univariate association between this ratio in patients while in hospital and one-year nonsurvival, ${ }^{35-38}$ although a multivariate study has not been published previously. Many of the classic symptoms and physical signs of cardiac failure correlated only weakly with the more objective measures, such as PEP/EP values. This too accords with previous reports. ${ }^{39}$ A significant univariate association was found in the present study between lung crepitations heard on day 5 and PEP/EP values on that day of $>0.33$, although not with values of $0 \cdot 30-0 \cdot 33$. There was a significant univariate association, however, between diuretic usage while the patient was in hospital and PEP/EP values of 0.30 0.33 on day 5 , as well as with higher values of this ratio. Lung crepitations, therefore, have limited prognostic value (table 1 ).

Evidence of pulmonary venous imbalance on the radiograph obtained routinely in the present study at the time of admission had some prognostic value. At the time this radiograph was obtained patients with even mild left ventricular failure are unlikely to have had time to respond to any diuretic medication to the extent that pulmonary venous imbalance would have gone. Indeed, in less severe cases the decision to give diuretic medication often was taken only after view-

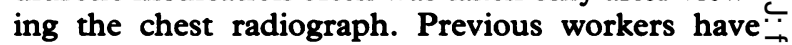
noted that patients with radiographic or other objec- $\overrightarrow{\vec{F}}$ tive evidence of left ventricular failure at the time of 0 admission are more likely to die within a year of 흐 discharge, ${ }^{40-42}$ even if the signs of failure resolve $\frac{\overline{\bar{c}}}{\overline{1}}$ during the first few days in hospital. ${ }^{43-46}$

It is uncertain why diuretic usage carried an

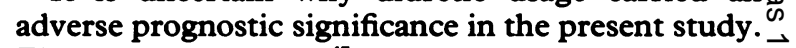
Electrolyte imbalance ${ }^{47}$ is unlikely to be the whole? explanation since patients who received only a single $\vec{\overrightarrow{ }}$ dose of a diuretic at the time of admission to hospital remained at increased risk throughout follow up, irrespective of whether any diuretic was given during follow up. Areas of ischaemic but still viable myocar- -0 dium may create a low left ventricular diastolic $A$ compliance during the early stages of an infarction, $\mathbb{C}$ and such patients would receive diuretic treatment 9 to relieve their pulmonary congestion. Areas of myocardial stiffness are known to improve while in hospital, ${ }^{48}$ enabling the diuretic to be stopped. The existence of areas of only marginally perfused 3 myocardium, however, may continue to pose a risk of $\Phi$ arrhythmias, ${ }^{49}$ even though collateral vessels may

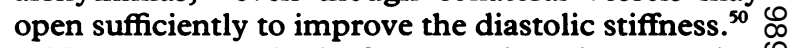

Numerous methods for assessing the pumping. effectiveness of the left ventricle have been used to predict survival after myocardial infarction, notably imaging with ultrasound, radionuclides, and $x$ ray contrast media. So far, however, none has been reported to predict survival with a combination of $\mathcal{Q}$ sensitivity, specificity, and accuracy ${ }^{105152}$ any better $\overrightarrow{0}$ than the six variables listed in table 3 .

The prognostic significance of ventricular extrasystoles and paroxysms of ventricular tachycardia on tape recorded electrocardiograms is still disputed. Paroxysms of ventricular tachycardia in one 24 hour recording are often absent the next day. ${ }^{53} \stackrel{?}{\sigma}$ Furthermore, frequent and complex ventricular 3 . extrasystoles seem to possess independent prognostic significance among patients with non- $Q$ wave infarc- $\frac{}{3}$ tions but not among those with $Q$ wave infarctions. ${ }^{54} \circ$ Ventricular arrhythmias are both more common and prognostically more sinister when recorded 2 weekso or more after infarction than when recorded, as in the present study, during the first week. ${ }^{55}$ Ventricularos extrasystoles have shown an independent prognostic $N$ significance when combined with a simple clinical N్ assessment of left ventricular function plus evidence ${ }_{-}$ from a chest radiograph, ${ }^{856-58}$ or with left ventricular ejection fractions derived from multiple gated ventriculography. ${ }^{59}$ The prognostic significance of $\stackrel{0}{?}$ ejection fractions may be enhanced multivariately by 0 including information on paroxysms of ventricularo tachycardia, ${ }^{360}$ on ventricular extrasystoles at a rate of $>3$ per hour ${ }^{3}$ or $>10$ per hour, ${ }^{6162}$ or on the ${ }^{\circ}$ complexity of the ventricular extrasystoles. ${ }^{63}$ These 
Table 4 Standardised canonical discriminant function coefficients calculated for the six most important monitored variables after dicotomisation

\begin{tabular}{|c|c|c|c|c|c|c|c|}
\hline $\begin{array}{l}\text { Dicotomised variable } \\
\text { Name }\end{array}$ & Value & $P E P / E P$ & $M I$ & $D M$ & Age group & Diuretic & $B B B$ \\
\hline PEP/EP: & $\begin{array}{l}<0.30 \\
>0.29\end{array}$ & $(0 \cdot 589)$ & $\begin{array}{l}0.341 \\
0.497\end{array}$ & $\begin{array}{l}0.560 \\
0.200\end{array}$ & $\begin{array}{l}0.348 \\
0.350\end{array}$ & $\frac{0.424 \star}{-}$ & $\frac{0 \cdot 215}{-}$ \\
\hline MI: & $\begin{array}{l}0 \\
>0\end{array}$ & $\begin{array}{l}0.366 \\
0.941\end{array}$ & $(0 \cdot 477)$ & $\underline{0}^{-581^{\star}}$ & $0.429 \star$ & $\begin{array}{l}0.287 \\
0.275\end{array}$ & $\begin{array}{l}0.139 \\
0.237\end{array}$ \\
\hline DM: & $\begin{array}{l}\text { Absent } \\
\text { Present }\end{array}$ & $0 \cdot 640^{\star}$ & $\underline{0.600 \star}$ & $(0 \cdot 345)$ & $\underline{-}^{0 \cdot 385^{\star}}$ & $\overline{0.818^{\star}}$ & $0.249^{\star}$ \\
\hline Age group: & $\begin{array}{l}<7 \\
>6\end{array}$ & $0.552^{\star}$ & $0.501^{\star}$ & $0 \cdot 406^{\star}$ & $(0 \cdot 281)$ & $0 \cdot 144^{\star}$ & $\overline{0 \cdot 726^{\star}}$ \\
\hline & $\begin{array}{l}\text { Not given } \\
\text { Given }\end{array}$ & $\begin{array}{l}0.939 \\
0.412\end{array}$ & $\begin{array}{l}0.596 \\
0.570\end{array}$ & $\begin{array}{l}0 \cdot 185 \\
0.462\end{array}$ & $\overline{0 \cdot 488 \star}$ & $(0.255)$ & $\overline{0.229}$ * \\
\hline BBB: & $\begin{array}{l}\text { Absent } \\
\text { Present }\end{array}$ & $\begin{array}{l}0.639 \\
1 \cdot 164\end{array}$ & $\begin{array}{l}0.511 \\
0.241\end{array}$ & $\begin{array}{l}0.430 \\
0.239\end{array}$ & $\begin{array}{l}0 \cdot 232 \\
0.349\end{array}$ & $\begin{array}{l}0.217 \\
0.697 \star\end{array}$ & $(0.094)$ \\
\hline
\end{tabular}

See footnote to table 3 for abbreviations. Values in parentheses are coefficients for undichotomised variables. ${ }^{\star}$ Variables where the two dichotomised values gave significantly different coefficients. Missing values are variables that failed to contribute multivariately to risk of death.

arrhythmias failed to enhance the success of predictions, when, as in the present study, combined with evidence of the extent of myocardial injury derived from biplane $x$ ray contrast ventriculography ${ }^{1415}$ or thallium imaging. ${ }^{13}$ Furthermore, radionuclide derived ejection fractions when combined with clinical evidence of ventricular dysfunction were no longer prognostically enhanced by information about ventricular arrhythmias. ${ }^{91012}$ Ventricular arrhythmias, therefore, probably reflect the extent of myocardial injury. The more fully the extent of injury has already been taken account of in a multivariate assessment of risk the less will be the additional contribution from ventricular arrhythmias. ${ }^{11}$ In one previous study: ${ }^{29}$ as in the present investigation, bundle branch blocks contributed multivariately to the risk of death in the year after myocardial infarction. In contrast with the previous study, however, patients in the present study with right and left bundle branch blocks had a similar mortality, which allowed data from them to be combined for statistical analysis.

The present study confirms previous work $^{2464}$ in showing that diabetes is an adverse prognostic feature that is independent of those others with which it often coexists (table 3 ). The adverse prognostic significance of several of the routinely monitored variables was different in diabetic and non-diabetic patients. Standardised canonical discriminant function coefficients were calculated for each of the prognostically important variables after patients were stratified in the ways shown in table 4 . In contrast with the situation among nondiabetic patients only diuretic use made an independent prognostic contribution among diabetic patients and warrants further study.

As in previous studies, ${ }^{29}$ age operated independently of the other prognostically important variables in the present study (table 3 ). In contrast with the situation among younger patients, however, the only routinely monitored variable that had an independent prognostic impact among those aged $>70$ years was the occurrence of bundle branch blocks (table 4). Note also that the age group to which a patient belonged did not make an independent contribution in those who had previously had a myocardial infarction, in the diabetics, and in those who did not receive a diuretic while in hospital (table 4). The reasons for these subgroup differences warrants further study.

In conclusion, within the first week it is possible to predict the risk of death for each patient recovering from an acute myocardial infarction. Only six items of information are required and assessment is possible entirely at the patient's bedside without resort to expensive, difficult, or dangerous investigations. Those found to be at some predetermined level of risk, say $50 \%$, warrant prophylaxis. ${ }^{6}$

I thank those many members of the staff of the Leicester Royal Infirmary who have helped me during the course of this study, particularly Dr J R Hearnshaw. Andrew Curry collaborated on the mathematical aspects of the study.

\section{References}

1 Marcus FI, Cobb LA, Edwards JE, et al. Mechanism of death and prevalence of myocardial ischemic symptoms in the terminal event after acute myocardial infarction. Am J Cardiol 1988;61:8-15.

2 Gilpin EA, Koziol JA, Madsen EB, Henning H, Ross J. Periods of differing mortality distribution during the first year after acute myocardial infarction. Am J Cardiol 1983;52:240-4.

3 Bigger JT, Fleiss JL, Kleiger R, Miller JP, Rolnitzky LM. The relationships among ventricular arrhy- 
thmias, left ventricular dysfunction, and mortality in the 2 years after myocardial infarction. Circulation 1984;69:250-8.

4 Goldstein S, Friedman L, Hutchinson R, et al. Timing, mechanism and clinical setting of witnessed deaths in postmyocardial infarction patients. $\mathrm{J} \mathrm{Am} \mathrm{Coll} \mathrm{Cardiol}$ 1984;3:1111-7.

5 Norris RM, Caughey DE, Deeming LW, Mercer CJ, Scott PJ. Coronary prognostic index for predicting survival after recovery from acute myocardial infarction. Lancet 1970;ii:485-8.

6 Antiplatelet Trialists' Collaboration. Secondary prevention of vascular disease by prolonged antiplatelet treatment. $\mathrm{Br} \mathrm{Med} J$ 1988;296:320-31.

7 Gottlieb SO, Gottlieb SH, Achuff SC, et al. Silent ischemia on Holter monitoring predicts mortality in high-risk postinfarction patients. JAMA 1988; 259:1030-5.

8 Kostis JB, Wilson AC, Sanders MR, Byington RP. Prognostic significance of ventricular ectopic activity in survivors of acute myocardial infarction who receive propranolol. Am J Cardiol 1988;61:975-8.

9 Tibbits PA, Evaul JE, Goldstein RE, et al. Serial acquisition of data to predict one-year mortality rate after acute myocardial infarction. $\mathrm{Am} J$ Cardiol 1987;60:451-5.

10 Ahnve S, Gilpin E, Henning H, Curtis G, Collins D, Ross J. Limitations and advantages of the ejection fraction for defining high risk after acute myocardial infarction. Am J Cardiol 1986;58:872-8.

11 Surawicz B. Prognosis of ventricular arrhythmias in relation to sudden cardiac death: therapeutic implications. J Am Coll Cardiol 1987;10:435-47.

12 Madsen EB, Gilpin E, Henning H, et al. Prediction of late mortality after myocardial infarction from variables measured at different times during hospitalization. Am J Cardiol 1984;53:47-54.

13 Hakki AH, Nestico PF, Heo J, Unwala AA, Iskandrian AS. Relative prognostic value of rest thallium-201 imaging, radionuclide ventriculography and 24 hour ambulatory electrocardiographic monitoring after acute myocardial infarction. J Am Coll Cardiol 1987;10:25-32.

14 Schulman SP, Achuff SC, Griffith LSC, et al. Prognostic cardiac catheterization variables in survivors of acute myocardial infarction: a five year prospective study. J Am Coll Cardiol 1988;11:1164-72.

15 Taylor GJ, Humphries JO, Mellits ED, et al. Predictors of clinical course, coronary anatomy and left ventricular function after recovery from acute myocardial infarction. Circulation 1980;62:960-70.

16 World Health Organization. Regional Office for Europe. Ischaemic heart disease registers: report of the fourth working group. Copenhagen: World Health Organization, 1970:30-48.

17 Northover BJ. Left ventricular systolic time intervals in patients with acute myocardial infarction. Br Heart $J$ 1980;43:506-13.

18 Northover BJ. The value of temporary electrical pacing for patients with acute myocardial infarction. Methods Inf Med 1984;23:23-8.

19 Greenberg H, Gillespie J, Dwyer EM. A new electrocardiographic classification for post-myocardial infarction clinical trials. Am J Cardiol 1987;59: 1057-63.

20 Killip T, Kimball JT. Treatment of myocardial infarction in a coronary care unit. A two-year $\stackrel{9}{+}$ experience with 250 patients. Am J Cardiol 1967; 20:457-64.

21 Northover BJ. Ventricular tachycardia during the first $\frac{\bar{\omega}}{T}$ 72 hours after acute myocardial infarction. Cardiology 1982;69:149-56.

22 Schamroth L. The disorders of cardiac rhythm. Oxford: Blackwell Scientific Publications, 1971:1-293.

23 Willems JL, Robles de Medina EO, Bernard R, et al. Criteria for intraventricular conduction disturbances $\vec{\omega}$ and pre-excitation. J Am Coll Cardiol 1985;5: 1261-75.

24 Lown B, Wolf M. Approaches to sudden death from coronary heart disease. Circulation 1971;44:130-42. के

25 Simson MB. Use of signals in the terminal QRS + complex to identify patients with ventricular 0 tachycardia after myocardial infarction. Circulation 음 $1981 ; 64: 235-42$.

26 Buckingham TA, Thessen CC, Stevens LL, Redd RM, $\square$ Kennedy HL. Effect of conduction defects on the signal-averaged electrocardiographic determination $\frac{\Phi}{3}$ of late potentials. Am J Cardiol 1988;61:1265-71.

27 Nie NH, Hull CH, Jenkins JG, Steinbrenner K, Bent DH. Statistical package for the social sciences. 2nd ed. $\overrightarrow{0}$ New York: McGraw-Hill, 1974:1-467.

28 Henning H, Gilpin EA, Covell JW, Swann EA, Orourke RA, Ross J. Prognosis after acute myocardial infarction: a multivariate analysis of mortality and survival. Circulation 1979;59:1124-36.

29 Bay KS, Lee SJK, Flathman DP, Roll JW, Piercy W. Application of step-wise discriminant analysis and Bayesian classification procedure in determining prognosis of acute myocardial infarction. Can Medo음 Assoc J 1976;115:887-92.

$30 \mathrm{Hsu}$ L, Senaratne MPJ, Desilva S, Rossall RE, Kappagoda T. Prediction of coronary events follow-? ing myocardial infarction using a discriminant function analysis. $J$ Chronic Dis 1986;39:543-52.

31 Muller JE, Ludmer PL, Willich SN, et al. Circadian variation in the frequency of sudden cardiac death. Circulation 1987;75:131-8.

32 Nicod P, Gilpin E, Dittrich $\mathrm{H}$, et al. Late clinicalô outcome in patients with early ventricular fibrillation after myocardial infarction. $\mathrm{J} \mathrm{Am}$ Coll Cardiolo 1988;11:464-70.

33 Tofler GH, Stone PH, Muller JE, et al. Prognosis after cardiac arrest due to ventricular tachycardia or ventricular fibrillation associated with acute myo- N cardial infarction (the MILIS study). Am J Cardiol $_{N}$ 1987;60:755-61.

34 Lawrie DM. Long-term survival after ventricular fibrillation complicating acute myocardial infarction Lancet 1969;ii:1085-7.

35 Boudoulas H, Sohn Y, Brown R, Weissler AM. Left ventricular dysfunction is a determinant of improved $\stackrel{\rho}{?}$ survival with beta-blockade therapy following 0 myocardial infarction. IRCS Med Sci 1985;13:271-2.

36 Brubakk O, Pedersen TR, Overskeid K. Noninvasive $\overparen{\mathbb{C}}$ evaluation of the effect of timolol on left ventricular $\frac{\rho}{\mathbb{D}}$ performance after myocardial infarction and the 
consequence for prognosis. J Am Coll Cardiol 1987;9:155-60.

37 Weissler AM. The systolic time intervals and risk stratification after acute myocardial infarction. $\mathrm{J} \mathrm{Am}$ Coll Cardiol 1987;9:161-2.

38 Weissler AM, O'Neill WW, Sohn YH, Stack RS, Chew PC, Reed AH. The prognostic significance of systolic time intervals after recovery from myocardial infarction. Am J Cardiol 1981;48:995-1002.

39 Eagle KA, Quertermous T, Singer DE, et al. Left ventricular ejection fraction. Physical estimates compared with gated blood pool scan measurements. Arch Intern Med 1988;148:882-5.

40 Battler A, Karliner JS, Higgins CB, et al. The initial chest $x$ ray in acute myocardial infarction. Prediction of early and late mortality and survival. Circulation 1980;61:1004-9.

41 Battler A, Slutsky R, Karliner J, Froelicher V, Ashburn W, Ross J. Left ventricular ejection fraction and first third ejection fraction early after acute myocardial infarction: value for predicting mortality and morbidity. Am J Cardiol 1980;45:197-202.

42 Wolffenbuttel BHR, Verdouw PD, Scheffer MG, Bom HPA, Bijleveld RE, Hugenholtz PG. Significance of haemodynamic variables in coronary care unit for prediction of survival after acute myocardial infarction. Br Heart $J$ 1983;50:266-72.

43 Dwyer EM, Greenberg H, Case RB. Association between transient pulmonary congestion during acute myocardial infarction and high incidence of death in six months. Am J Cardiol 1986;58:900-5.

44 Greenberg H, McMaster P, Dwyer EM. Left ventricular dysfunction after acute myocardial infarction: results of a prospective multicenter study. $\mathrm{J} \mathrm{Am}$ Coll Cardiol 1984;4:867-74.

45 Warnowicz MA, Parker H, Cheitlin MD. Prognosis of patients with acute pulmonary edema and normal ejection fraction after acute myocardial infarction. Circulation 1983;67:330-4.

46 Nicod P, Gilpin E, Dittrich $\mathrm{H}$, et al. Influence on prognosis and morbidity of left ventricular ejection fraction with and without signs of left ventricular failure after acute myocardial infarction. $A m J$ Cardiol 1988;61:1165-71.

47 Stewart DE, Ikram H, Espiner EA, Nicholls MG. Arrhythmogenic potential of diuretic induced hypokalaemia in patients with mild hypertension and ischaemic heart disease. Br Heart $J$ 1985;54:290-7.

48 Schelbert HR, Henning H, Ashburn WL, Verba JW, Karliner JS, Orourke RA. Serial measurements of left ventricular ejection fraction by radionuclide angiography early and late after myocardial infarction. Am J Cardiol 1976;38:407-15.

49 Sniderman AD, Beaudry JP, Rahal DP. Early recognition of the patient at late high risk: incomplete infarction and vulnerable myocardium. Am J Cardiol 1983;52:669-73.

50 Schwartz H, Leiboff RL, Katz RJ, et al. Arteriographic predictors of spontaneous improvements in left ventricular function after myocardial infarction. Circulation 1985;71:466-72.

51 Fioretti P, Brower RW, Simoons ML, et al. Relative value of clinical variables, bicycle ergometry, rest radionuclide ventriculography and 24 hour ambulatory electrocardiographic monitoring at discharge to predict 1 year survival after myocardial infarction. J Am Coll Cardiol 1986;8:40-9.

52 Fioretti P, Brower RW, Lazzeroni E, et al. Limitations of a QRS scoring system to assess left ventricular function and prognosis at hospital discharge after myocardial infarction. Br Heart $J$ 1985;53:248-52.

53 Winkle RA, Peters F, Hall R. Characterization of ventricular tachyarrhythmias on ambulatory ECG recordings in post-myocardial infarction patients: arrhythmia detection and duration of recording, relationship between arrhythmia frequency and complexity, and day-to-day reproducibility. Am Heart $J$ 1981;102:162-9.

54 Maisel AS, Scott N, Gilpin E, et al. Complex ventricular arrhythmias in patients with $Q$ wave versus non- $Q$ wave myocardial infarction. Circulation 1985;72:963-70.

55 Olson HG, Lyons KP, Troop P, Butman SM, Piters KM. Prognostic implications of complicated ventricular arrhythmias early after hospital discharge in acute myocardial infarction: a serial ambulatory electrocardiography study. Am Heart $J$ 1984; 108:1221-8.

56 Kostis JB, Byington R, Friedman LM, Goldstein S, Furberg C. Prognostic significance of ventricular ectopic activity in survivors of acute myocardial infarction. J Am Coll Cardiol 1987;10:231-42.

57 Bigger JT, Weld FM, Rolnitzky LM. Prevalence, characteristics and significance of ventricular tachycardia (three or more complexes) detected with ambulatory electrocardiographic recording in the late hospital phase of acute myocardial infarction. $\mathrm{Am} \mathrm{J}$ Cardiol 1981;48:815-23.

58 Davis HT, Decamilla J, Bayer LW, Moss AJ. Survivorship patterns in the posthospital phase of myocardial infarction. Circulation 1979;60:1252-8.

59 Schulze RA, Strauss HW, Pitt B. Sudden death in the year following myocardial infarction. Relation to ventricular premature contractions in the late hospital phase and left ventricular ejection fraction. $\mathrm{Am} \mathrm{J} \mathrm{Med}$ 1977;62:192-9.

60 Bigger JT, Fleiss JL, Rolnitzky LM. Prevalence, characteristics and significance of ventricular tachycardia detected by 24-hour continuous electrocardiographic recordings in the late hospital phase of acute myocardial infarction. $\mathrm{Am} J$ Cardiol 1986;58:1151-60.

61 Mukharji J, Rude RE, Poole WK, et al. Risk factors for sudden death after acute myocardial infarction: two year follow-up. Am J Cardiol 1984;54:31-6.

62 Multicenter Postinfarction Research Group. Risk stratification and survival after myocardial infarction. $N$ Engl J Med 1983;309:331-6.

63 Rapaport E, Remedios P. The high risk patient after recovery from myocardial infarction: recognition and management. J Am Coll Cardiol 1983;1:391-400.

64 Smith JW, Marcus FI, Serokman R. Prognosis of patients with diabetes mellitus after acute myocardial infarction. Am J Cardiol 1984;54:718-21. 